\title{
I Would Have Had More Success If...: Student Reflections On Their Performance In Online And Blended Courses
}

\author{
G. Sherrie Lewis, Virginia State University, USA
}

\begin{abstract}
Anecdotal research is a common phenomenon in the study of distance education. In an effort to review some of the factors that affect student satisfaction, an existing instrument was used to gauge learner perceptions of online interaction/communication, learning and performance, collaboration, hardware and software issues and the quality of support. According to some authors, use of samples of convenience and small study populations, the conclusions drawn by $Y u$ and Brandenburg (2006) could not be generalized across differing student populations. In an effort to create some generalizable conclusions regarding student perceptions, surveys contained some of Yu and Brandenburg's (2006) inquiries on communication, interaction, perceptions of the instructor, course materials and the availability of student support services in online and blended courses. Questions on student demographic data were also included. The purpose of this study is to examine some of the ideas associated with existing distance education research. It was hypothesized that students would have had more success if 1) they had more time to interact with other students, 2) knew what the course expectations were prior to registration, c) they had access to a newer computer, and 4) they had administrative support.
\end{abstract}

Keywords: Distance Education, Student Perceptions, Management

\section{INTRODUCTION}

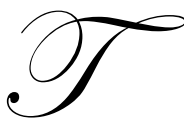

he United States Census Bureau (2001) reports that $51 \%$ of households in the United States own one or more computers. The advent of computers, CD-ROMs, email, chat rooms, bulletin boards, and video conferencing has led to education that is delivered to students on demand (Gendreau, 2003,

Markel, 1999, and Rumble, 2000). Technological innovation has resulted in a medium of instruction used by corporations, secondary and post-secondary institutions of higher learning. In 2003, businesses spent more than $\$ 9$ billion on continuing education worldwide. By 2004, educational spending increased by $133 \%$ to generate more than $\$ 12$ billion (Sarker \& Nicholson, 2005). Corporations also support use of distance learning for full-time employees and geographically dispersed workers. The medium helps organizations provide on-demand instruction that reduces the costs associated with use of physical facilities, loss of productivity and travel (Evans \& Hasse, 2001, and Holley, 2002). As a result, technology has hastened the need for new knowledge and skills; the characteristics of learners are changing (Holley, 2002, and Morales \& Roig, 2002).

Older workers with full-time jobs and families now demand educational opportunities that allow them to meet both professional and familial obligations. An increase in the popularity of business related majors and a changing student population have resulted in expanding business programs in public and private institutions. Distance education programs allow for-profit and nonprofit schools to expand their reach and decrease costs per student through economies of scale. As a result of an increasing demand for college level education, many institutions are creating or expanding distance education courses and programs. Online business education is a growing discipline whose majors represent three-fifths of the 1,700 institutions of higher learning (Moore, 2003). These new courses meet the needs of students at public, private and for-profit institutions. Thus, universities use distance education to meet the needs of local and geographically dispersed traditional and non-traditional students 
(Bower \& Hardy, 2004, and Moore, 2003). Thus, distance education courses help to improve the access to higher education for working adults. Cheaper technology, convenience and recent demand for additional educational opportunities are factors that have helped distance education to grow each year by 25\% to 33\% from 1992-1998 (Evans \& Hasse, 2001, and Holley, 2002). The demand for post-secondary education is expected to increase by $16 \%$ within the next 10 years (Jones, 2003). In fact, distance learning programs report an average $41 \%$ growth rate (Gunawardena \& McIsaac, 2003).

The demand is expected to grow as non-traditional students return to school in search of new job skills or with hopes of updating their current skill sets. These efforts allow universities to use their brand equity to attract new students (Ives, 2006). Consequently, institutions can now offer additional management courses and degree programs without expanding their physical plants (Keegan, 1999). Distance education allows learners to study at any place and at any time (Fujimoto, 2002, Keegan, 1994, and Markel, 1999). During the 2000-2001 academic year, $56 \%$ of 2-year and 4-year institutions offered distance education courses (Bryant, Kahle \& Schafer, 2005, Chernish, DeFranco, Lindner \& Dooley, 2005, and Holley, 2002).

Students now seek course attributes that include the following: 1) promotion of active engagement, 2) encouragement of reflective learning, 3) aiding deeper processing, 4) a record of discussion, 5) new opportunities for group working and social interaction, 6) easily accessible global resources, and 7) involvement of diverse groups (Evans \& Hasse, 2001). These students have the following characteristics: full-time employees, aged 25-54 with annual incomes of $\$ 45,000$ or more. Evans and Hasse (2001) believe demographics, such as gender, current level of educational attainment, geographic area, and market size, have little to no impact on online business education (Holley, 2002). Distance education experts have attempted to establish a relationship between the demographics of online business education students and the skills they demand. These demands are based on students' desire to change careers, earn promotions, or obtain employment. In fact, $85 \%$ of corporations subsidize distance education for their employees (Markel, 1999).

These changes have led to increasing demand for distance education courses at most institutions. Management educators' opinions of distance education differ. Issues related to this topic include quality, accreditation and student satisfaction. Both types of instruction provide students with information that promotes learning. Distance education involves many of the principles used in traditional education (ION, 2006). Consequently, experts assess the effectiveness of distance education by comparing outcomes, such as grades and student satisfaction, to that of students in face-to-face courses. However, differences in course management systems, faculty competency, student demographics, and instructional techniques make comparisons difficult (Demirdjian, 2002, and McLaren, 2004). An absence of original research has led to a series of studies in which validity and reliability are difficult to prove. A main reason is that instruments (quizzes, exams, questionnaires and scales) may or may not measure the studied behaviors, skills and attributes that they were intended to measure. Other reasons for difficulty associated with demonstrating reliability and validity include the novelty of the medium and the assumption that classroom instruction is the exemplary method against which all media are measured (Gondhalekar et al, 2002).

Institutional policies also determine classification of dropouts and length of terms. Although retention is a source of concern for traditional and distance education programs, some distance education opponents maintain that the problem is caused by the medium (Demirdjian, 2002, and Webster \& Hackley, 1997). Although experts have been able to identify many of the behaviors exhibited by dropouts, there is an absence of definitive explanations of the process by which students drop out of institutions of higher education (Tinto, 1975). Hence, these factors vary from one institution to another. In fact, Carr (2000) stated that the dropout rates can be 10 to $20 \%$ higher than those for students enrolled in traditional courses. Those who remain often report lower levels of satisfaction with their online courses (Priluck, 2004). Differences in dropout rates for traditional and distance education students also tend to skew the results of studies (Gondhalekar et al., 2002, and Merisotis, 1999). Hence, there is no theoretical or conceptual framework for the study of the effectiveness of distance education. As a result, studies are not standardized or easily replicated. Thus, experts' opinions of distance education differ. 


\section{THE STUDY}

Distance education advocates believe the medium improves students' technology skills and requires written expression that helps to improve student writing, idea development and critical thinking (Bourne, 1997, Close et al., 2005, Dupin-Bryant, 2004, and Hawkes, 2001). Students who miss class have an opportunity to skip familiar course content, review lessons and instructor comments (Lincoln, 2001, and MacGregor, 2001). Repetition allows nontraditional learners to gain the skills necessary to compete in the classroom. Elimination of travel time and flexible scheduling allow greater exposure to the materials for distance education students (Cavanaugh, 2005, Tesone et al., 2003, and Wyatt, 2005). Wade and Power (1998) reported those students' subject material immersion results in greater learning. The solitary environment helps students to develop self-discipline, critical thinking and written communication skills (MacGregor, 2001).

Some experts oppose distance education because they believe that students experience lower levels of satisfaction (Clarke et. al., 2001, Clow, 1999, and McLaren, 2004). Similarly, Navarro and Shoemaker (2000) found that $49 \%$ of traditional students chose not to take an online section of an economics course because they felt "more comfortable in a traditional learning environment." Twenty percent chose not to take the course because they "didn't think they would learn as much" as students in traditional classes (Navarro \& Shoemaker, 2000). Student satisfaction levels are associated with a host of issues. They include learner isolation, motivation and levels of comfort with the medium.

Distance education outcomes assessments have produced mixed results. Characteristics of successful online learners include self-motivation and directedness (Allen et al., 2002, and Wang \& Newlin, 2002). Although some educational experts report that distance education deprives traditional undergraduate students of socialization and interpersonal communication skills, others argue that working students already possess these skills (Chung, 2005, and Tesone et al., 2003). Cavanaugh (2005) states that distance education courses appeal to academically talented nontraditional students who are unable or unwilling to make the commute to campus. The results of McLaren's (2004) study indicated that distance education students had higher GPAs compared to their classmates who enrolled in face-to-face formats or those who dropped online courses. Basile and D'Aqila (2002) found that distance education students report a greater level of satisfaction when taking online courses. McLaren (2004), Allen et al (2002), and Hiltz (1997) found that students in online courses report satisfaction and learning rates that are equal to those of students in face-to-face courses. Factors influencing these findings include the level of course interactivity, student involvement and instructor contact (Priluck, 2004). These components were measured by analyzing student responses in post-course surveys.

Course surveys are used to identify issues that are important to administrators and faculty. Relevant topics include communication, interaction, course requirement and the availability of student support services (Yu \& Brandenburg, 2006). Due to use of samples of convenience and small sample sizes, the conclusions drawn by Yu and Brandenburg (2006) could not be generalized across differing student populations. Differences in course content, instructional efforts and learner entry levels may affect the outcomes of various studies (Billings \& Bachmeier, 1994, and Tallent-Runnels et al, 2006). According to the Yu and Brandenburg study (2006), instructors assumed that students would have had more success if 1) they had more time to interact with other students, 2) knew what the course expectations were prior to registration, 3) they had access to a newer computer, and 4) had administrative support. The subsequent study was undertaken using the same hypotheses.

In an effort to create some generalizable conclusions regarding student perceptions, the survey incorporates some of $\mathrm{Yu}$ and Brandenburg's (2006) questions on communication, interaction, perceptions of the instructor, course materials and the availability of student support services. Questions on student demographic data were also included so that student demographics could serve. The purpose of this study is to analyze student perceptions of success factors and rationale for enrolling in distance education courses.

The survey was completed by School of Business students who had taken online or blended management courses at a state-funded, historically black university. It was administered through use of Qualtrics Software by five instructors in various management courses. Student volunteers received a link to the survey from five instructors who taught required management courses. Of 244 students who began the voluntary survey, 234 
completed the instrument and 182 surveys were usable. For purposes of this study, incomplete responses and surveys on non-business courses were not tabulated. The survey was open for a period of three weeks.

Students were allowed to complete one survey for each online or blended management course they completed over the last two academic years. Table 1depicts the percentage of students who reported taking online and blended courses by discipline and experience level.

Table 1: School of Business Distance Education Participants by Concentration and Experience Level 2008-2010

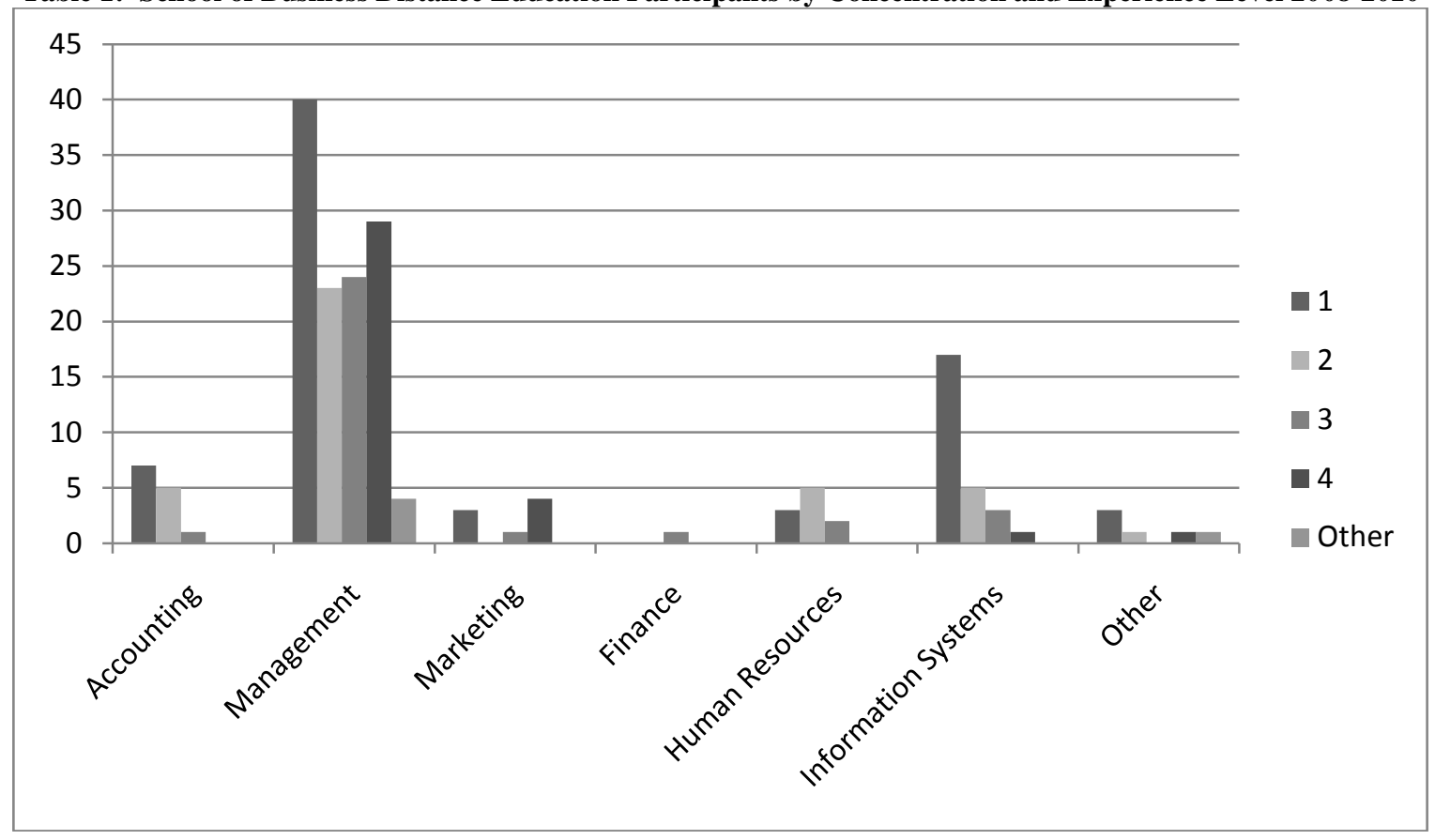

Management students make up the largest percentage of the business school population $(n=120)$. Computer Information Systems majors make up the second largest population $(n=26)$. Consequently, management courses make up the majority of classes offered within the School of Business. Online course offerings included electives and required introductory management and marketing courses, internships, organizational behavior, organizational theory, consumer behavior, business statistics, finance advertising and information systems. As a result, management students demonstrated the most experience with online courses. In fact, management majors reported taking the most online courses. None the less, $60 \%$ of all learners participating in this survey reported taking two or more online courses. Students had the ability to choose between online and traditional sections of each course. Students participated in information sessions or class meetings that served as online classroom orientations. Instructors held virtual and face-to-face office hours. Thus, $83 \%$ of survey participants indicated that they felt comfortable in the online environment. These results indicate that students some students may prefer online courses if given a choice between the two mediums.

Students' cumulative experience with online courses does indicate a cumulative level of knowledge with the medium. However, $43 \%$ of students participating in the survey indicated that they wished they had more interaction with other students in the course. In spite of instructor use of discussion questions, blogs, chat rooms and Wikis, students indicated a need for additional opportunities for student-to-student interaction. Similarly, 50\% of students indicated a wish for additional interaction with the instructor. Students in Yu and Brendberg's (2006) study reported a high level of satisfaction with the level of interaction they experienced in the course ( $\mathrm{n}=13$, mean 4.67). Due to size of this population, student perspectives may not be representative of the population. However, results of the current study do coincide with an assessment of online student perceptions and their motivation to work independently. Table 2 contains a description of student success factors and learner responses by experience level. 
Table 2: Student Perceptions \& Experience

I would have had more success in this online course if my home computer had been newer or if I had a...

I would have had more success in this course if I had understood which text was required PRIOR to re...

I would have had a better understanding of the expectations of this online course if I had been able...

I would have had more success in this course if I had more opportunities to interact with students.

I would have had more success in this course if I had more opportunities to interact with the instructor...
Strongly Disagree

\begin{tabular}{cccccc}
\multicolumn{4}{l}{ I have taken the following number of online courses: } \\
$\mathbf{1}$ & $\mathbf{2}$ & $\mathbf{3}$ & $\mathbf{4}$ & Other & Total \\
2 & 4 & 11 & 5 & 0 & $\mathbf{2 2}$
\end{tabular}

Disagree

Neither Agree nor Disagree

Agree

Strongly Agree

Strongly Disagree

Disagree

Neither Agree nor Disagree

Agree

Strongly Agree

Strongly Disagree

Disagree

Neither Agree nor Disagree

Agree

Strongly Agree

Strongly Disagree

Disagree

Neither Agree nor Disagree

Agree

Strongly Agree

Strongly Disagree

Disagree
Neither Agree nor Disagree
Agree
Strongly Agree
Total

$\begin{array}{cccccc}16 & 3 & 3 & 4 & 0 & \mathbf{2 6} \\ 17 & 11 & 12 & 13 & 1 & \mathbf{5 4} \\ 22 & 12 & 3 & 9 & 0 & \mathbf{4 6} \\ 15 & 9 & 3 & 4 & 3 & \mathbf{3 4} \\ 4 & 5 & 8 & 4 & 0 & \mathbf{2 1}\end{array}$

$\begin{array}{cccccc}15 & 10 & 7 & 5 & 1 & \mathbf{3 8} \\ 32 & 9 & 11 & 13 & 0 & \mathbf{6 5} \\ 19 & 10 & 3 & 11 & 0 & \mathbf{4 3} \\ 5 & 6 & 3 & 2 & 3 & \mathbf{1 9} \\ 2 & 1 & 4 & 3 & 0 & \mathbf{1 0}\end{array}$

$\begin{array}{cccccc}24 & 7 & 9 & 4 & 1 & \mathbf{4 5} \\ 27 & 10 & 8 & 11 & 0 & \mathbf{5 6} \\ 14 & 16 & 7 & 8 & 0 & \mathbf{4 5} \\ 5 & 5 & 4 & 9 & 3 & \mathbf{2 6} \\ 3 & 4 & 5 & 7 & 0 & \mathbf{1 9}\end{array}$

$\begin{array}{cccccc}16 & 7 & 6 & 5 & 1 & \mathbf{3 5} \\ 18 & 8 & 6 & 16 & 0 & \mathbf{4 8} \\ 31 & 14 & 12 & 7 & 0 & \mathbf{6 4} \\ 4 & 6 & 3 & 0 & 3 & \mathbf{1 6} \\ 1 & 3 & 3 & 7 & 0 & \mathbf{1 4}\end{array}$

\begin{tabular}{cccccc}
17 & 5 & 5 & 5 & 0 & $\mathbf{3 2}$ \\
17 & 10 & 8 & 9 & 1 & $\mathbf{4 5}$ \\
28 & 14 & 13 & 12 & 0 & $\mathbf{6 7}$ \\
9 & 7 & 3 & 2 & 3 & $\mathbf{2 4}$ \\
$\mathbf{7 2}$ & $\mathbf{3 9}$ & $\mathbf{3 2}$ & $\mathbf{3 5}$ & $\mathbf{4}$ & $\mathbf{1 9 2}$ \\
\hline
\end{tabular}

Twenty-seven percent of students reported that they are "learning to be self-motivated but are not as disciplined as they need to be" while $12 \%$ reported that they need "more guidance to perform to their full potential". Four percent reported that they felt "uneasy about performing without immediate classroom feedback". Thus, $43 \%$ of respondents expressed some form of concern with their ability to perform in their online and blended courses. This group also demonstrated the least amount of experience in the online classroom. Student opinions of the flexibility and level of learning associated with their distance education experience may indicate that they have not had enough exposure to the medium to build confidence in it. In contrast, $74 \%$ of students indicated that flexible deadlines enabled them to be successful in the course. These factors could be explained by some of the inherent characteristics associated with distance learning.

Online and blended courses contained a variety of learning tools. Examples include online lectures, PowerPoint presentations, videos, cases, online student presentations and handouts delivered via Blackboard. A text 
was required for each course. These tools are often used in the traditional sections of the same courses and were used to cater to students with diverse learning styles. Table 3 depicts the School of Business distance learner population by learning style and level of experience.

Table 3: Learning Style \& Experience

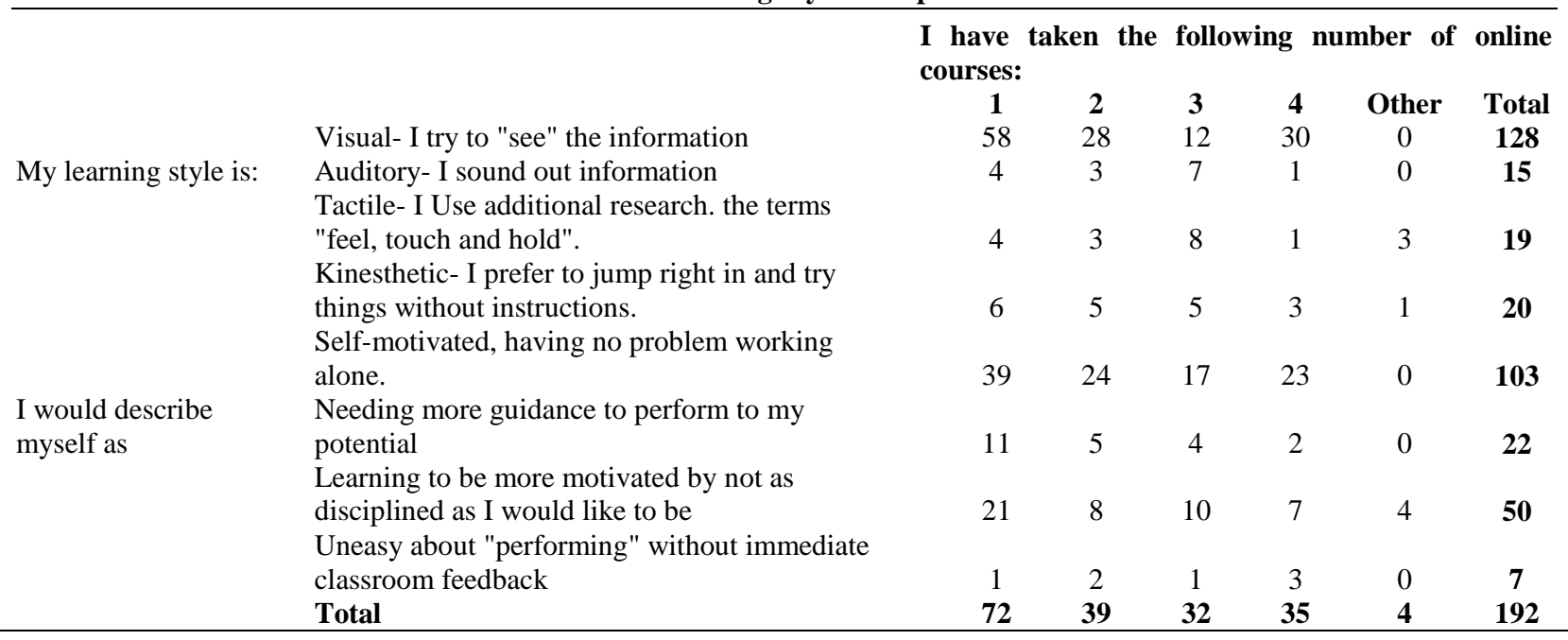

Approximately $70 \%$ of all distance education participants identified themselves as visual learners at each level of experience. Forty-three percent of visual learners reported taking one online course. However, visual served as the dominant learning style for students who had taken only one course at the time of the survey with $80 \%$ of participants selecting visual learning as their primary learning style. Other frequently chosen learning styles include kinesthetic $(11 \%)$ and tactile learning $(10 \%)$.

Eight percent of students indicated that they had an auditory learning style. It is important to note that as students became more experienced in the online classroom, they began to cite other methods as preferred learning styles. Thus, experienced learners became proficient in multiple modalities. Of students who reported taking one online course, $19 \%$ chose a method other than visual learning as a preferred style. Of students whose experience included two online courses, $29 \%$ of students selected a method other than visual learning as their preferred style. Sixty-three percent of students taking three online courses chose methods other than visual learning as their preferred style. None of the students who took five or more online courses cited visual learning as preferred style. In contrast, $85 \%$ students who took four online courses cited visual as their preferred style. This difference corresponds with course and faculty development initiatives that occurred during the last two semesters. Efforts included participation distance learning certificate programs, workshops and distance learning seminars. These changes could also indicate a continuing need for instruction that caters to diverse learning style preferences. In doing so, faculty may also need to create orientation and administrative tools that meet needs that meet these learners.

Online courses were not offered during the first semester of the distance education initiative. Courses were limited to blended offerings during the first semester. Blended and traditional sections of the same course were often taught by the same instructor. Blended courses were replaced by fully online courses during semester two of the initiative. These courses were then replaced by blended course offerings in subsequent semesters. One of the major differences between the Yu and Brandenberg (2006) study is that two-thirds of students reported that they did not receive accurate information about the course. In contrast, $62 \%$ of students agreed or strongly agreed that they received accurate course information prior to preregistration. These findings are consistent with students' perceptions the importance of the text and syllabus. 
Thirty-four percent of students agreed or strongly agreed that they could have been more successful if they understood which text was required prior to registration. Similarly, 39\% agreed or strongly agreed that they could have been more successful if they'd had access to the syllabus prior to registration. Hence, the availability of information is vital to the online student success. Faculty serves as advisors at the institution described in this study. Online courses were offered through the Division of Continuing Education. Students who participated in the initial $\mathrm{Yu}$ and Brandenberg study (2006) contacted a separate office for registration and course information. Thus, institutional differences often result in differences in student responses to some questions. However, students in both studies indicated that general course information is a success factor.

Technical support numbers were located on course syllabi and the home page. During orientation, students received handouts that contained technical support numbers along with instructions on required hardware and software. The University's BlackBoard Welcome Page contains a list of required add-ons and related links. None the less, $44 \%$ agreed or strongly agreed that they would have been more successful if their home computer had been newer or if they had access to a computer laboratory with newer equipment. In contrast, $60 \%$ participants in the $\mathrm{Yu}$ and Brandenberg (2006) study agreed or strongly agreed that would have been more successful if their home computer had been newer or if they had access to a computer laboratory with newer equipment. These differences may also be explained by differences in organizational structure. Students in the current student often utilized labs housed in the same building as faculty who taught their online courses. Students often received technical assistance from instructors who taught the online courses.

\section{CONCLUSION}

It was hypothesized that students would have had more success if 1) they had more time to interact with other students, 2) knew what the course expectations were prior to registration, 3) they had or had access to a newer computer, and 4) had administrative support (Yu \& Brandenberg, 2006). The instrument was modified to include demographic data and was used to test these ideas in another environment. A survey of 182 students indicated that the success factors had been correctly identified. However, students in the current study identified a preference for other types of interaction (student-to-instructor rather than student-to-student). Differences in University structure also influence roles and responsibilities associated with advising and administrative support for online and blended courses. Therefore, students in the current study received advisement but did not have information on details associated with the course (i.e., syllabus and textbook information). Both populations identified ownership or access to a new computer as a success. Orientations, labs and instructor proximity to those labs helped to decrease the occurrences of this success factor for the University involved in the second study. While students who participated in the current study seemed satisfied with registration, activities, they identified a need for additional information that affected performance in distance education courses. Although anecdotal in nature, the $\mathrm{Yu}$ and Brandenberg study (2006) serves as a tool that Universities can use to determine student needs and success factors.

Differences in student demographics, level of instruction, the availability of resources and faculty experience are often unique to each institution. However, student wants and needs are often similar. As the popularity of distance education continues to grow, faculty and administrators will gain a greater sense of tools that aid student success.

\section{AUTHOR INFORMATION}

G. Sherrie Lewis is an Assistant Professor of Management in the School of Business at Virginia State University in Petersburg, VA. Correspondence may be sent to gsherrielewis@gmail.com or PO Box 9209, Petersburg, VA 23806.

\section{REFERENCES}

1. Bower, B. \& Hardy, K. (Winter 2004). From correspondence to cyberspace: Changes and challenges in distance education. New Directions for Community Colleges 128, 5-12.

2. Bryant, S., Kahle, J. \& Schafer, B. (August 2005). Distance education: A review of the contemporary literature. Issues in Accounting Education, 20(3) 255-272. 
3. Carr, S. (2000). As distance education comes of age, the challenge is keeping the students. Chronicle of Higher Education, 46(23), 39-41.

4. Chernish, W., DeFranco, A., Linder, J., \& Dooley, K. (2005). Does it matter? Analyzing the results of three different delivery methods. The Quarterly Review of Distance

5. Education, 6(2), pp 87-95.

6. Chien, Y., \& Brandenburg, T. (2006). I Would Have Had More Success If...: The Reflections and Tribulations of a First-Time Online Instructor. Journal of Technology Studies, 32(1), 43-52. Retrieved from Academic Search Complete database.

7. Demirdjian, Z. (March 2002). The virtual university: Is it a panacea or a Pandora's box? Journal of American Academy of Business, 1(2) 172.

8. Evans, J. \& Hasse, I. (2001). Online business education in the twenty-first century: An analysis of potential target markets [Electronic Version]. Internet Research, 11(3), 246-261.

9. Fujimoto, T. (2002). Online learning versus classroom learning. EDSPSY421. The Pennsylvania State University. Retrieved, 18 October, 2005 from

http://scholar.google.com/scholar?hl=en\&lr=\&q=cache:RKTqH4WaAvsJ:www.personal.psu.edu/users/t/u/ tuf105/studies/INSYS421ProjectPaper.pdf+author:\%22Fujimoto\%22+intitle:\%22Literature+research:+Co mparative+research+on+online+...\%22.

10. Gendreau, R. (2003). What has happened in the business world of on-line distance learning? Journal of American Academy of Business 2(2), 446-451

11. Gondhalekar, V., Barnett, R. \& Barthelmes, D. (2002). Online vs. in-class: Comparison based on some non-survey dimensions. Retrieved September 27, 2005 from http://207.36.165.114/FMAOnline/Vijay.pdf

12. Gunawardena, C. \& McIsaac, M. (2003). Distance Education, Retrieved November 18, 2005 from http://seamonkey.ed.asu.edu/ mcisaac/dechapter/

13. Holley, D. (2002). Which room is the virtual seminar in please? [Electronic version]. Education \& Training, 44(3), 112-121.

14. Ives, K. S. (2006). Community colleges and distance learning. Journal of Asynchronous Learning Networks, 10(3), 85-94.

15. ION Illinois Online Network (n.d.). Instructional strategies for online courses. Retrieved February 18, 2006 from http://www.ion.uillinois.edu/resources/tutorials/pedagogy/instructionalstrategies.asp

16. Jones, R. (2003). A recommendation for managing the predicted growth in college enrollment at a time of adverse economic conditions. Online Journal of Distance Learning Administration (6)1. Retrieved March 17, 2010 from: http://www.westga.edu/\%7Edistance/ojdla/spring61/jones61.htm .

17. Keegan, D. Editor: (1999). Foundations of distance education. (3rd ed.). Routledge: New York.

18. Markel, M. (1999). Distance education and the myth of the new pedagogy. [Electronic version]. Journal of Business and Technical Communication, 13(2), 208-222.

19. McLaren, C. (2004). A comparison of student persistence and performance in online and classroom business statistics experiences, Decision Sciences Journal of Innovative Education, 2(1), 1-10.

20. Merisotis J. \& Phipps, R. (1999). What's the difference? A review of contemporary research on the effectiveness of distance learning in higher education. Prepared for the American Federation of Teachers, Retrieved on July 25, 2006 from 1999http://64.233.187.104/search?q=cache:7qyOM4SgyOUJ:www.ihep.com/Pubs/PDF/ Difference.pdf+\%22Merisotis $\% 22+\% 22 *+s+*+$ difference+*\%22\&hl=en.

21. Moore, M. (2003). From Chautauqua to the virtual university: A century of distance education in the United States. Retrieved February 1, 2006 from http://www.cete.org/acve/docs/distance.pdf\#search=\%22\%22Moore\%22\%20\%22Chautauqua\%20*\%20*\% 20Virtual\%20University\%22\%22

22. Morales, L. \& Roig, G., (2002). Connecting a Technology Faculty Development Program with Student Learning. Campus-Wide Information Systems, 19(2), 67-72.

23. Priluck, R. (2 August 2004). Web-assisted courses for business education: An examination of two sections of principles of marketing. Journal of Marketing Education, 26(2), 161-173.

24. Rumble, G. (2000). Student support in distance education in the 21 st century: Learning from service management [Electronic version]. Distance Education, 21(2), 216-235.

25. Tinto, V. (1975). Drop-out from higher education: A theoretical synthesis of recent research. Review of Educational Research, 45(1), 89-125. 
26. United States Census Bureau. (2000). Computer Use in the United States, Retrieved December 1, 2005 from http://www.census.gov/prod/2005pubs/p23-208.pdf

27. Sarker \& Nicholson, 2005, Exploring the myths about online education in information systems. Informing Science Journal 8, 55-73. Retrieved March 17, 2010 from http://citeseerx.ist.psu.edu/viewdoc/download?doi=10.1.1.105.9680\&rep=rep1\&type=pdf.

28. Webster, J. \& Hackely, P. (1997). Teaching effectiveness in technology-mediated distance learning. Academy of Management Journal, 40(6), 1282-1309. 
NOTES 